\title{
Thermo Mechanical Analysis of Composite Cylinder Liners using Finite Element Analysis
}

\author{
Vidya Ch, P. Phani Prasanthi and K. Sivaji Babu \\ Department of Mechanical Engineering, P. V. P. Siddhartha Institute of Technology, Kanuru, Vijayawada - 520007, \\ AndhraPradesh, India; vidyachaparala29@gmail.com, pprasanthi.parvathaneni@gmail.com, \\ k_sivajibabu@yahoo.co.in
}

\begin{abstract}
Background/Objective: Cylinder liners are very important part of an automobile engine and working of the liner directly affects the engine performance. Conventional cylinder liners are being replaced with high temperature composite materials. The present work is to identify the performance of cylinder liners under combined mechanical and thermal load in terms of radial, longitudinal and hoop stresses by selecting different high temperature composite materials. Methods/ Findings: Different high temperature composite materials such as Carbon/Polyimide, Woven Carbon/Phenolic, Woven Graphite Phenolic, Carbon/Carbon composite, Boron/Aluminum, Silicon/Carbide composite cylinder liners are analyzed by applying pressure and thermal load. The variation in the radial stresses $\left(\sigma_{r}\right)$, longitudinal stresses $\left(\sigma_{1}\right)$ and hoop stresses $\left(\sigma_{\theta}\right)$ are identified for selected materials. Thermo mechanical strains in radial, axial and circumferential directions are also identified. The analysis is performed by Finite element based software ANSYS. Solid 8node 183 elements are selected to perform the analysis. The Fe models are validated with the analytical equations. Application: Among all the materials considered in the analysis, Carbon/Carbon composite performance is good under considered loading and boundary conditions. Compared to all the stresses, the severity of axial stresses is more than radial and hoop stresses. The present work is used for the effective design of cylinder liners with high temperature composite materials.
\end{abstract}

Keywords: Axial Stress, Cylinder Liner, Finite Element Method, High Temperature Composite Materials, Hoop Stresses, Radial Stresses

\section{Introduction}

A continuous demand for economy, quality of internal combustion engine leads to the development of automobile engines. The development of an automobile engine is perceived in two aspects. One is to reduce the fuel consumption, so that the cost of the automobile maintenance as well as global worming will be decreased. Another aspect is to decrease the weight of the engine which interns decrease the fuel consumption. The weight of the engine will be decreased by replacing the already used conventional materials by new materials. Composite materials are replacing traditional materials because of their strength to weight ratio and stiffness to weight ratio ${ }^{1}$. The objective of the present authors is used to replace the conventional cylinder liners with composite material to increase the strength to weight ratio. Many authors studied the cylinder liners, engine parts in the view of material and production process. $\mathrm{In}^{1}$ studied the gray cast iron cylinder liners of an automobile with the surface hardening process. The authors studied the micro hardness distribution of the hardened cylinder layers in order to evaluate the quality of the hardened layers. $\mathrm{In}^{2}$ investigated both the distribution of the contact pressure on the gasket and the stresses of the cylinder head at different loading conditions, such as cold assembly, hot assembly, cold start and hot firing by numerical calculation based on the Finite Element Method (FEM). Thermal resistances between liners and engine blocks are nondestructively studied by Photo thermal infrared thermography ${ }^{3}$. The wear condi-

*Author for correspondence 
tion of the marine diesel engine cylinder is studied by using simulation techniques ${ }^{4}$. Designing and analysis of cylinder liner of a marine engine by using a titanium alloy (grade 4) was performed by ${ }^{5}$ using the Finite Element Method. A 4 stroke diesel engine of SANTRO vehicle cylinder liners was analyzed under thermo-mechanical loading by using Finite Element Method for Nickelchromium alloy by $\underline{6}$.

From the above observations, it is found that the cylinder liners will be analyzed effectively with the Finite Element Method and not extensive work has done on the selection of composite material to increase the performance of cylinder liners. The objective of the present work is to explore the variation of radial, axial and hoop stresses for various high temperature composite materials using Finite Element Method.

\section{Finite Element Procedure}

A cylinder liner is modeled by considering the inner diameter of $0.15 \mathrm{~m}$ and thickness of $0.01 \mathrm{~m}$. The length of the cylinder liner is taken as $0.5 \mathrm{~m}$. Solid 8 node 183 elements with axisymmetric option is selected to convert the geometrical model into the finite element model. The cylinder liner geometrical model is shown in Figure 1.a and the finite element mesh on the cylinder liner is shown in Figure 1.b.

The cylinder liner considered for the study is restricted to move in the axial direction by arresting the deformations in all aspects i.e. radial, axial and circumferential direction on the top and bottom area of the liner (Figure 2). For the combined thermo mechanical loading, a uniform pressure of $60 \mathrm{~N} / \mathrm{m}^{2}$ is applied in the inner area of the cylinder. Along with the pressure load, temperature of $1750 \mathrm{~K}$ is applied in the same area. Different high temperature materials such as Carbon/polyimide, Woven Carbon/Phenolic, Woven Graphite Phenolic, Carbon/ Carbon composite, Boron/Aluminum, Silicon/Carbide cylinder liners is considered for the study. The material properties of the above materials are provided in the reference $^{7-11}$.

\subsection{Validation of FE Procedure}

The Finite Element Models are validated with the analytical expressions for radial and hoop stresses under pressure load. Table 1 provides the closeness between the FE results and analytical calculated results. The Fe results are obtained by taking a steel cylinder liner with inner diameter of $60 \mathrm{~mm}$ and outer diameter $100 \mathrm{~mm}$, subjected to an internal pressure of $60 \mathrm{MPa}$. The Young's modulus of steel is taken as $200 \mathrm{GPa}$ and the Poisson's ratio is 0.3 . The same element Solid 8 node 183 is selected to perform the analysis. The radial and hoop stresses are obtained from FE approach and compared to analytical solution. Pi and Po are the internal and external pressure respectively. ri and ro are the inner and outer radius of the cylinder liner.

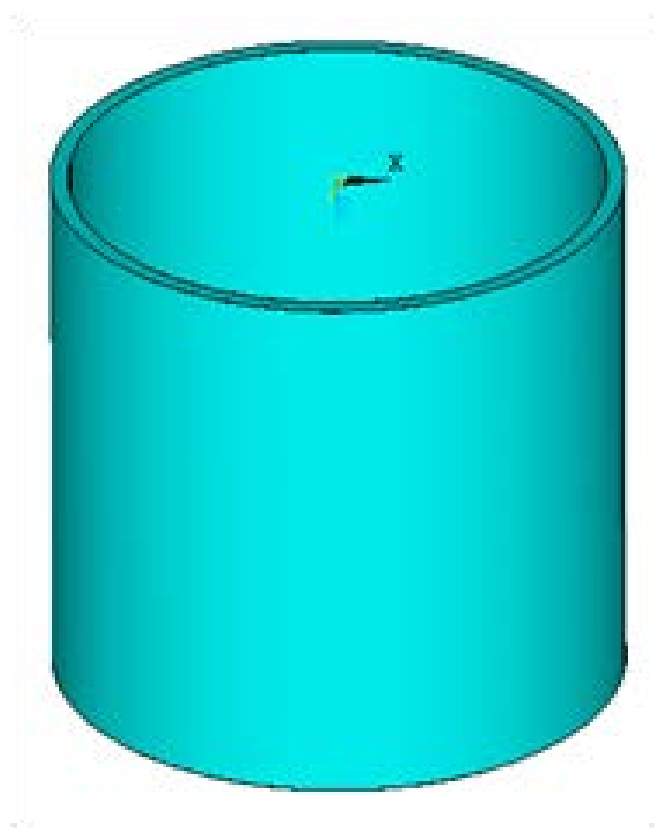

Figure 1.a. Geometrical model.

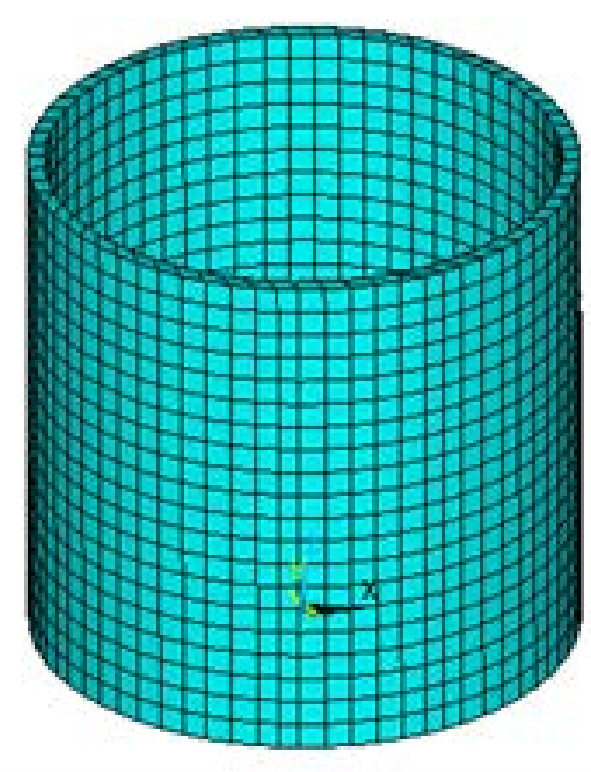

Figure 1.b. Finite element model of cylinder liner. 


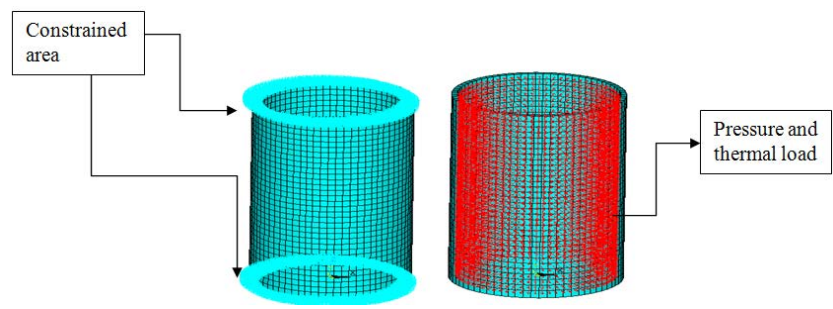

Figure 2. Loading and boundary conditions on FE model.

Table 1. Validation of FE results with analytical equations

\begin{tabular}{|l|l|l|l|l|l|}
\hline S.No & Stress Type & \multicolumn{2}{|l|}{$\mathbf{R}=\mathbf{r i}$} & \multicolumn{2}{l|}{$\mathbf{R}=$ ro } \\
\hline 1. & $\begin{array}{l}\text { Radial stress } \\
(\mathrm{MPa})\end{array}$ & -63.5 & -63.5 & 0.025 & 0.025 \\
\hline 2. & $\begin{array}{l}\text { Hoop Stress } \\
(\mathrm{Mpa})\end{array}$ & 71.5 & 71.5 & 135.72 & 135.72 \\
\hline
\end{tabular}

\section{Results And Discussions}

The objective of the present work is to estimate the stresses induced in the cylinder liners due to combined loading such as pressure and thermal loading conditions. Figure 3 shows the variation of radial stress in different materials. From this it is observed that Carbon/Carbon composite liners showed more resistance to radial stress than other materials considered for the study. Next best material to suppress the radial stress is Carbon/Polyimide. And there is no difference in radial stresses for the composite liners prepared with woven Carbon/Phenolic, woven Graphite/ Phenolic, Boron/Aluminum and silicon carbide/Al. The radial stress $\left(\sigma_{\mathrm{r}}\right)$ contour is shown in Figures 4-9.

Figure 8 shows the variation of longitudinal stresses in different materials. Compared to all the other stress, the magnitude of longitudinal stress is more. Maximum stresses are observed for woven Graphite/Phenolic and minimum stress is observed for liners made with Carbon/ Polyimide and Carbon/Carbon composite. The distribution of these stress contours is shown in Figure 5. Figure 9 shows the variation of hoop stresses under combined loading of different materials. No considerable changes in these stresses are observed for different materials. i.e. the magnitude of hoop stress is constant for the liners made with different materials considered for the analysis. Figure 6 shows the contour of hoop stress of a composite liner.

Figures 10-13 shows the variation of total thermal and mechanical strain for different materials as these cylinder liners are subjected to combined mechanical and thermal load. The combined thermal and mechanical strain is high for woven Carbon/Phenolic and woven Graphite/Phenolic and for the rest of the materials these strains are negligible in radial direction (Figure 10). The magnitude of combined strain in the axial and circumferential direction is more than radial direction (Figures 11-12). Carbon/Polyimide, Woven Carbon/Phenolic, Woven Graphite Phenolic cylinder liners strain is more than other materials considered for the study in the axial and circumferential directions also the same trend is observed for combined shear strain (Figure13).

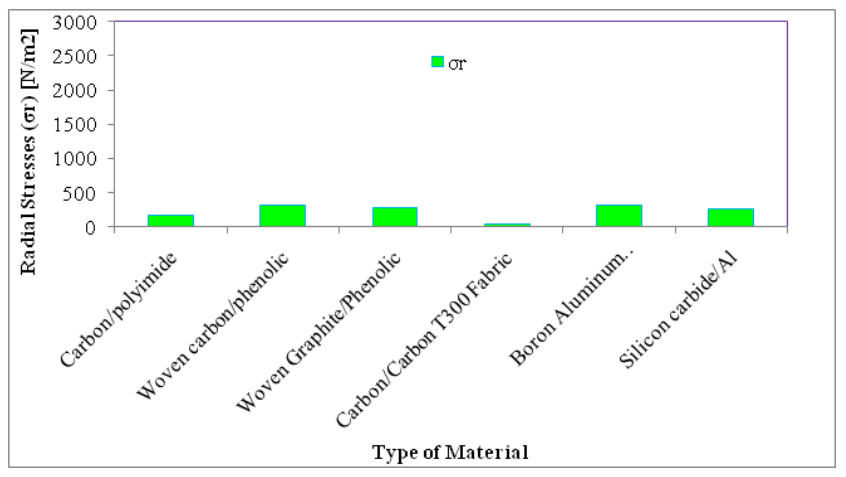

Figure 3. Variation of radial stress ( $\sigma r)$ for different materials.

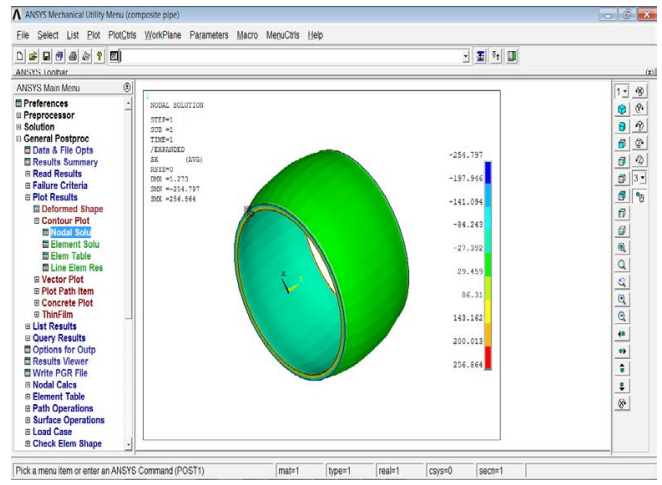

Figure 4. Radial stress (or) contour.

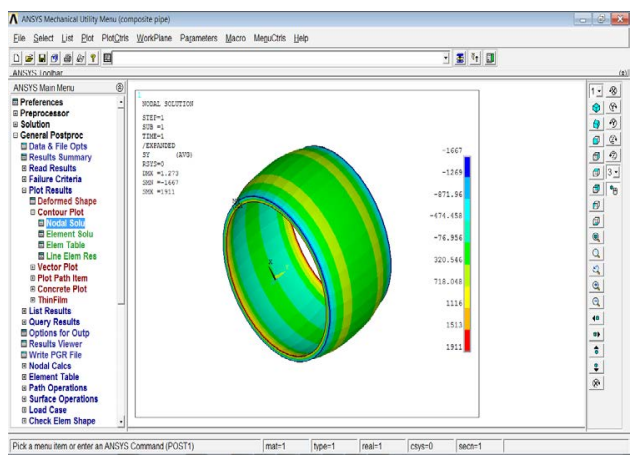

Figure 5. Axial stress $(\sigma \mathrm{l})$ contour. 


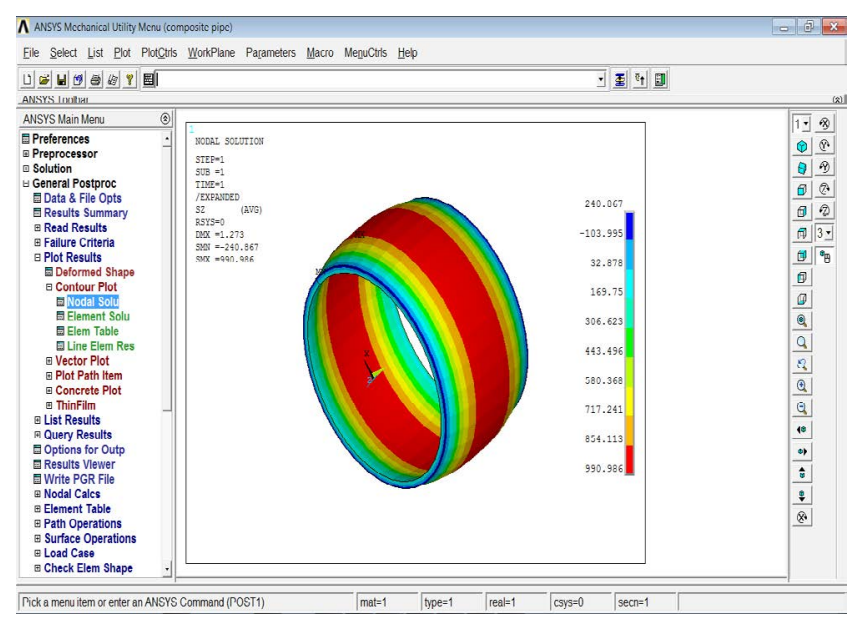

Figure 6. Hoop stress ( $\sigma r)$ contour.

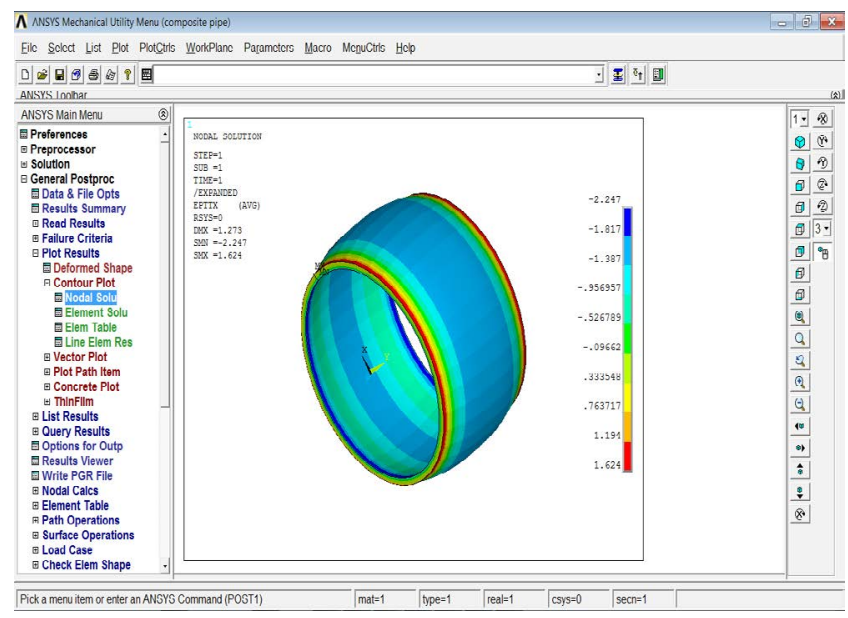

Figure 7. Total mechanical and thermal strain contour.

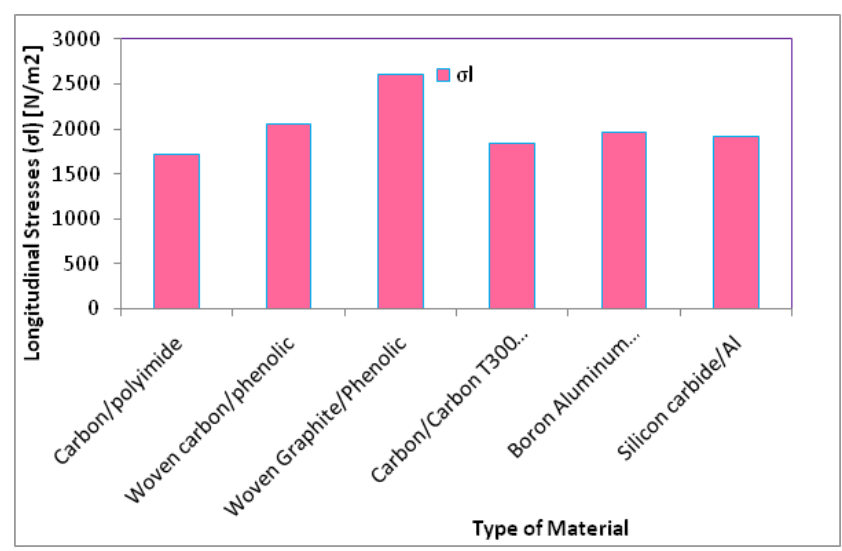

Figure 8. Longitudinal stresses $\left(\sigma_{1}\right)$ for different material.

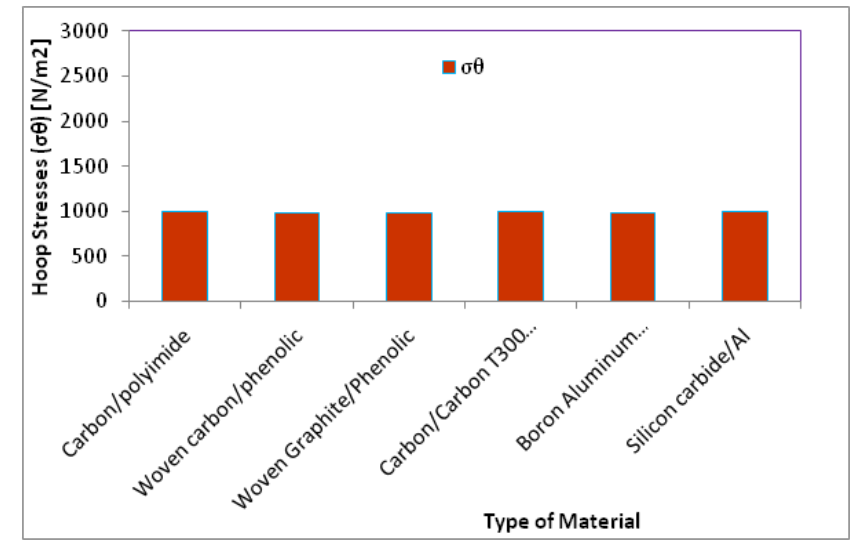

Figure 9. Hoop stresses $\left(\sigma_{\theta}\right)$ for different material.

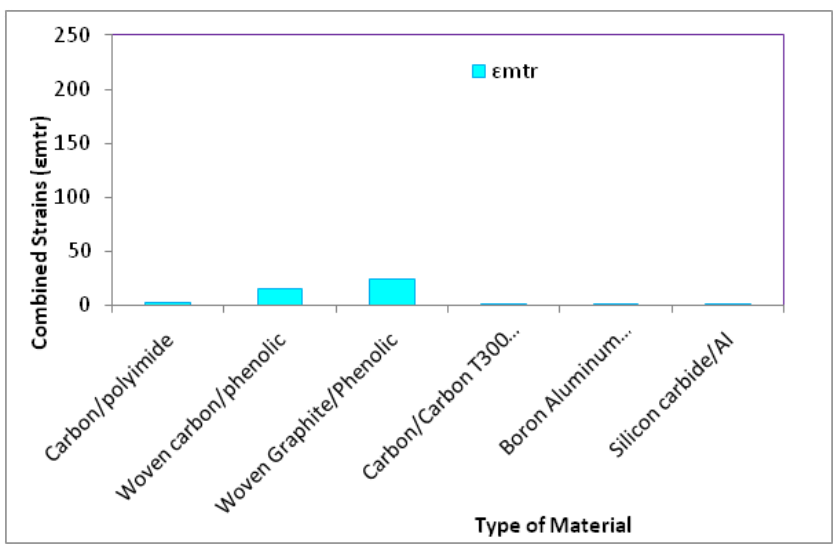

Figure 10. Total mechanical and thermal strain $\left(\varepsilon_{\mathrm{mtr}}\right)$ in radial direction for different material.

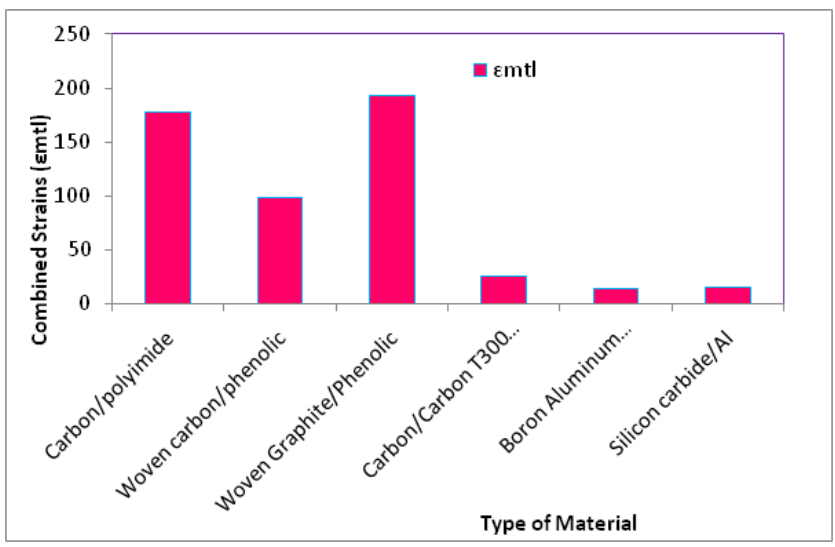

Figure 11. Total mechanical and thermal strain $\left(\varepsilon_{\mathrm{mtt}}\right)$ in axial direction for different material. 


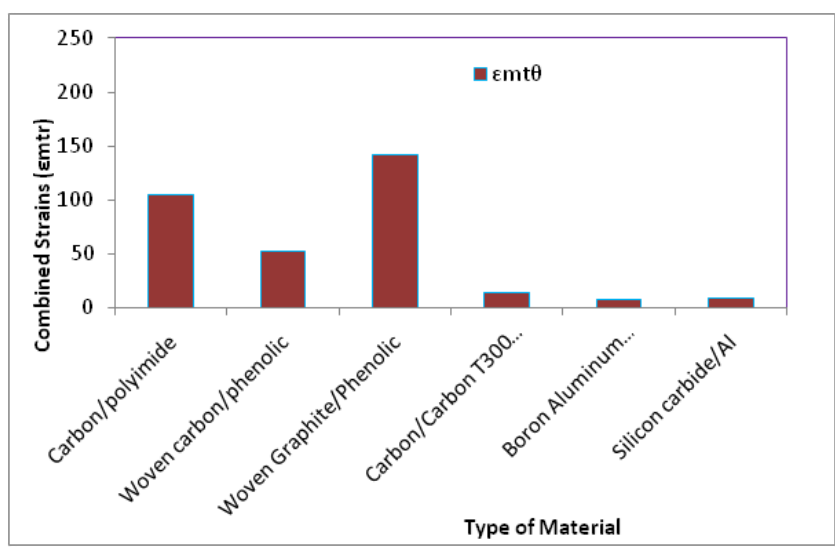

Figure 12. Total mechanical and thermal strain $\left(\varepsilon_{\mathrm{mtt}}\right)$ in axial direction for different material.

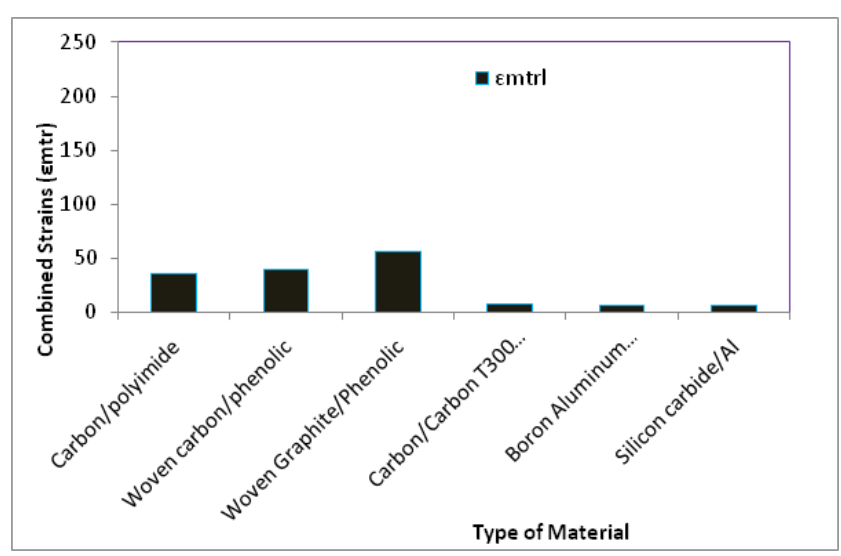

Figure 13. Total mechanical and thermal shear strain $\left(\varepsilon_{\text {mtrl }}\right)$ for different material.

\section{Conclusions}

Thermo mechanical analysis of cylinder liners for different materials is evaluated by using the Finite Element Method. The variation of radial, axial and hoop stresses of cylinder liners along with the combined strains in respective directions is explored. The following conclusions are obtained from the present work.

- The magnitude of axial stress is more in cylinder liners compared radial and hoop stress due to combined pressure and thermal loads.

- The cylinder liner with Carbon/Carbon composite shows good resistance to stress than all the materials considered for the analysis.

- The hoop stress intensity is same for the different materials considered for the analysis.

- Combined thermo mechanical strain is evaluated for different composite materials. At this point of view, Carbon/Carbon composite, Boron/ Aluminum, Silicon/Carbide, Silicon/Carbide Ceramic composite showed less strain than Carbon/Polyimide, Woven carbon/Phenolic, Woven Graphite Phenolic composite liners.

- From this work, it is suggested to use Carbon/ Carbon composite liners or Boron/ Aluminum composite liners composite liners in an automobile engine to increase the performance under thermo mechanical loading.

\section{References}

1. Analysis of laser surface hardened layers of automobile engine cylinder liner. 2007. https://www.sciencedirect. com/science/article/pii/S1006706X07600107

2. Lee CC, Chiang KN, Chen WK, Chen RN. Design and analysis of gasket sealing of cylinder head under engine operation conditions. Finite Elements in Analysis and Design. 2005; 41(11):1160-74. https://doi.org/10.1016/j.finel.2004.12.007

3. Laloue P, Bissieux C, Henry JF, Pron H, Ecolier JL, Nigon F. Infrared nondestructive measurement of thermal resistance between liner and engine block: Design of experiment. International Journal of Thermal Sciences. 2008; 47(3):24960. https://doi.org/10.1016/j.ijthermalsci.2007.02.012

4. Jensen MF, Bottiger J, Reitz HH, Benzon ME. Simulation of wear characteristics of engine cylinders. Wear. 2002; 253(910):1044-56. https://doi.org/10.1016/S0043-1648(02)00251-X

5. Kamlesh SS, Mishra R, Kumari N, Gupta JK. FEA and thermal analysis of cylinder liner of marine engine using titanium alloy. Journal of Material Science and Mechanical Engineering. 2015; 2(8):9-14.

6. Shinde S, Jadhav PV, Jadhav DB. Thermo mechanical analysis of cylinder liner. International Journal of Engineering Research and General Science. 2016; 4(3):1-11.

7. Delozier DM, Waston KA, Ghose S, Working DC, Connell JW, Smith JG, Sun YP, Lin Y. Thermal conductivity of polyimide/carbon nanofiller blends. Key Engineering Materials. 2007; 334-335:749-52. https://doi.org/10.4028/www.scientific.net/KEM.334-335.749

8. Schuster J, Heider D, Sharp K, Glowania M. Thermal conductivities of three-dimensionally woven fabric composites. Composites Science and Technology. 2008, 38 (9), pp. 20852091. https://doi.org/10.1016/j.compscitech.2008.03.024

9. Shaira M, Yousef S. Modification of aluminum 6063 microstructurebyaddingboronandtitanium toimprovethethermal conductivity. Journal of Materials. 2018; 8905-469:1-6. https://doi.org/10.1155/2018/8905469

10. Daniel IM, lshai O. Engineering mechanics of composite materials. 2nd ed. Oxford University Press; 2006. 
11. Prasanthi P, Sambasiva Rao G, Umamaheswar Gowd B. Mechanical performance of Buckminster fullerenereinforced composite with interface defects using Finite
Element Method through homogenization techniques. Composite Interfaces, Taylor and Francis. 2015; 22(4):299314. https://doi.org/10.1080/09276440.2015.1021223 